\title{
Temporal arteritis: a form of systemic panarteritis
}

\author{
A Sendino, F J Barbado, I González-Anglada, E Antón, F López-Barea, J J Vázquez
}

\begin{abstract}
The case is reported of a patient with giant cell arteritis affecting several organs. The triggering cause of death was a brainstem infarction due to basilar artery thrombosis. The necropsy showed the systemic character of the disease affecting the coronary, bronchial, and ovarian arteries.
\end{abstract}

(Ann Rheum Dis 1992; 51: 1082-1084)

Giant cell arteritis, also called temporal arteritis, is a systemic panarteritis which affects large, medium, and small sized arteries especially in elderly patients. ${ }^{12}$ Most of the clinical symptoms and signs are caused by vasculitis of the carotid branches and hence temporal arteritis is the most characteristic clinical form. There are various systemic forms, however, both atypical and mixed, which affect multiple organs with or without clinical symptoms. ${ }^{3}$

Among the most troublesome problems of giant cell arteritis are the long term treatment with steroids and recurrences after discontinuing drug treatment.

We describe here a patient with giant cell arteritis whose death was caused by a stroke with basilar artery thrombosis. The necropsy showed an active multisystemic arteritis with unusual locations: coronary arteries, bronchial arteries, and female reproductive tract arteries. From a clinical and biological point of view the disease had been suppressed by 26 months of treatment with steroids.

\section{Case report}

In April 1987 an 81 year old woman with a past history of non-dysfunctional multinodular goitre for five years and hypertension was admitted to hospital after having a headache over the temporal regions and muscle weakness (especially over the scapular region) for one month. Thirty hours before admission she had a sudden loss of vision in her left eye.

Laboratory studies revealed an erythrocyte sedimentation rate (ESR) of $110 \mathrm{~mm}$ in the first hour, a haemoglobin concentration of $106 \mathrm{~g} / \mathrm{l}$, and $\alpha_{2}$ globulin $13 \cdot 3 \%$. Temporal arteritis was suspected and prednisone $(60 \mathrm{mg}$ daily) was started in the emergency room. The patient improved.

Prednisone was gradually reduced to $8 \mathrm{mg} /$ day and maintained at that level. It was discontinued 26 months later after the patient's disease became clinically and biochemically stable.

In August 1989 she presented with a transient ischaemic attack including disorientation and dysarthria. She was treated with an antiplatelet drug (dipyridamole). In September 1989 she had severe weakness, arthralgia, and arthritis of the wrists. The ESR was again markedly increased $(102 \mathrm{~mm} / \mathrm{h})$. The symptoms were thought to be a recurrence of temporal arteritis and steroid treatment was reintroduced.

In October 1989 the patient presented with a sudden onset of agitation, loss of speech, deviation of labial commissure to the left, and motor deficiency in the right limbs. Physical examination showed a temperature of $39^{\circ} \mathrm{C}$, grade III coma, dehydration, left paralytic mydriasis, and right superior facial nerve palsy. Both temporal artery pulses were present. There were no meningeal signs. In the right hand and foot we found hypotonia, hemiparesis, a positive Babinski's sign, and also a necrotic lesion of the great and second toes of the right foot and the great toe of the left foot. Peripheral artery pulses were normal. The laboratory data included an ESR of $130 \mathrm{~mm}$ in the first hour. The cerebrospinal fluid was clear, the glucose concentration was $5.8 \mathrm{mmol} / \mathrm{l}$ (simultaneous blood glucose $7 \cdot 2 \mathrm{mmol} / \mathrm{l}$ ), and protein $0.5 \mathrm{~g} / 1$. Microorganisms were not found with Gram's stain. A chest radiograph showed cardiomegaly and left parahiliar condensation. A computer assisted tomographic brain scan showed corticosubcortical atrophy. An electrocardiogram showed atrial fibrillation and a lateral subendocardial ischaemic lesion. The electroencephalogram showed interhemispheric asymmetry with signs of severe brain damage in the left hemisphere.

The patient remained in a coma with fever. She did not improve and died six days later.

The necropsy showed histological lesions of giant cell arteritis in the following arteries: both superficial temporal (fig 1), both coronary (fig 2), paraovarian (fig 3), and peribronchial (fig 4). A basilar artery thrombosis from the posterior cerebral triggered an infarction of the left hemimesencephalon and the ipsilateral occipital lobe.

\section{Discussion}

The case has been reported of a patient with temporal arteritis whose diagnosis was made based on clinical data. ${ }^{45}$ The patient showed a good response to treatment with steroids for 26 months. After that period of time the treatment was discontinued because of an alleviation of the symptoms and on the basis of laboratory analyses. Three months later she had a recurrence of temporal arteritis with neurological complica- 
tions and died. The necropsy showed the systemic character of the disease with multiple organs affected..$^{46}$

We found damage in various locations

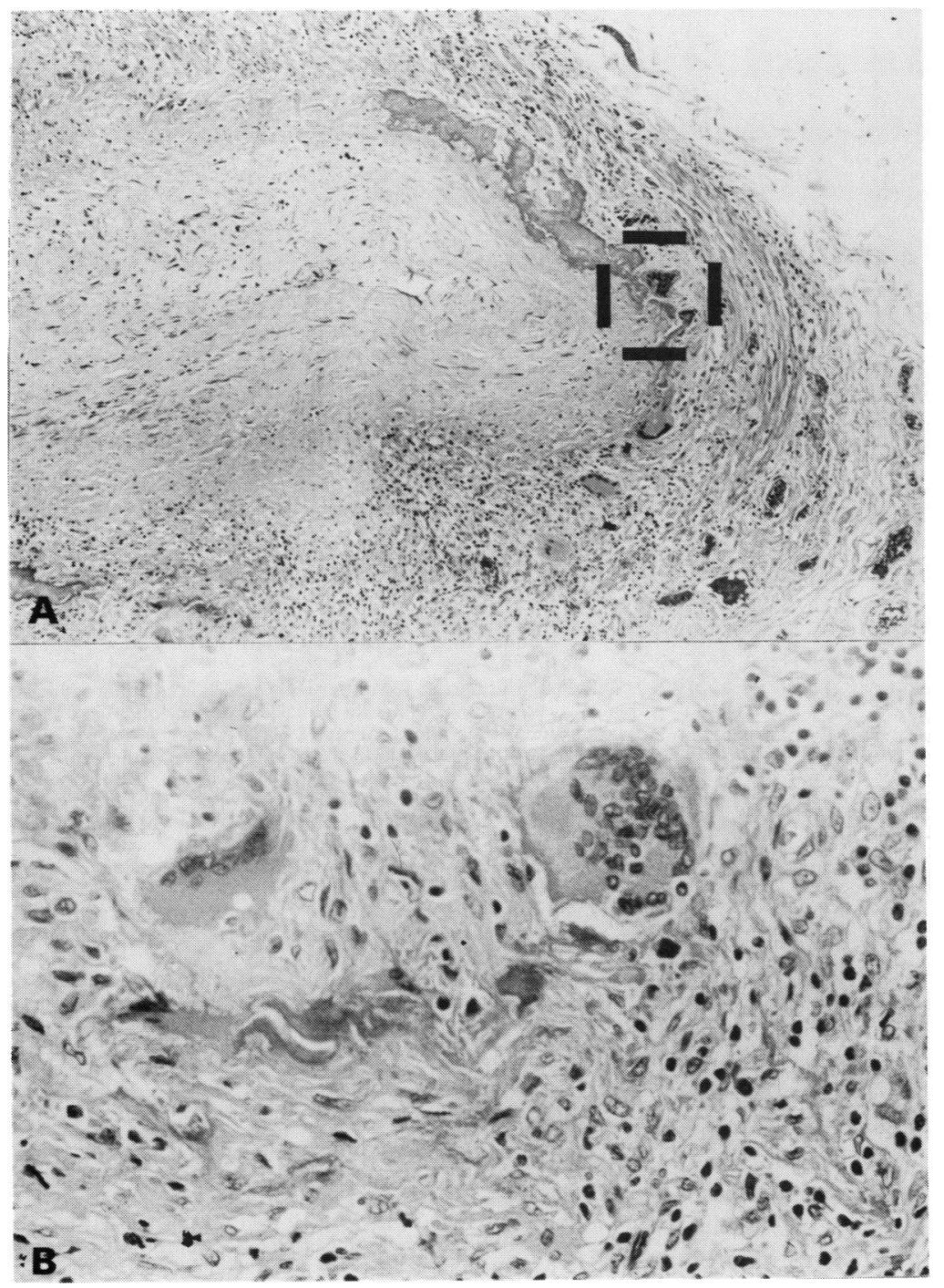

Figure 1 (A) Superficial temporal artery showing narrow lumen, intimal thickening, heavy medial and adventicial inflammation, destruction of the internal elastic lamina, and granulomatous infiltration. (B) Giant cells phagocytising the internal elastic lamina (haematoxylin and eosin stains).

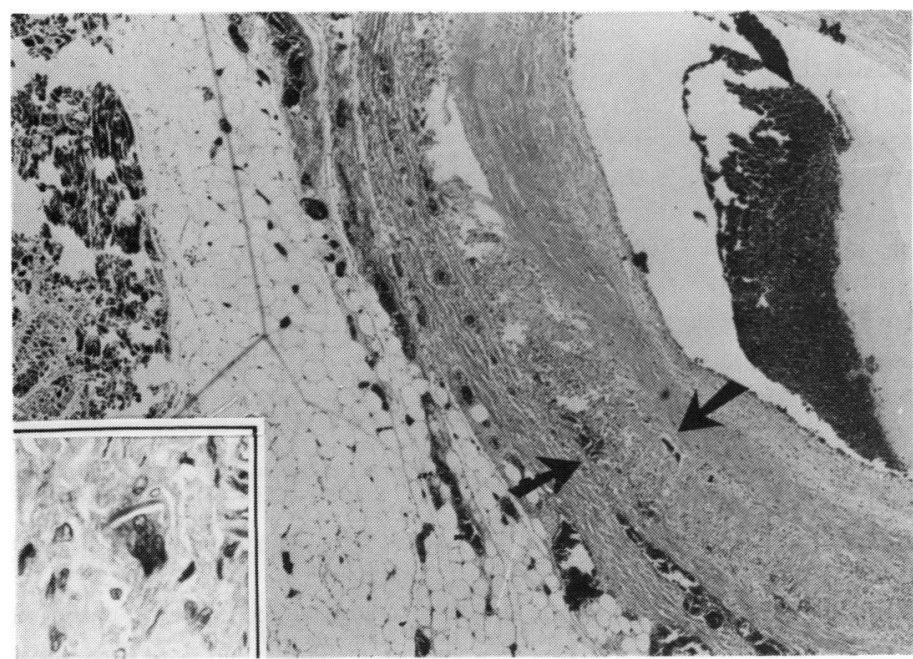

Figure 2 Midsegment of the epicardial left anterior descending coronary artery with focally granulomatous giant cell arteritis showing fragmentation of the elastic interna lamina (arrows). Lower left corner inset shows a giant cell phagocyting fragmentation of elastic interna lamina (haematoxylin and eosin stains). including the external carotid system (temporal arteries) (fig 1), the heart (coronary arteries) (fig 2 ), the lung (peribronchial arteries) (fig 4), and the genital tract (ovarian artery) (fig 3). The triggering cause of the patient's neurological manifestations was a severe thrombosis of the basilar artery with left hemimesencephalic and ipsilateral occipital lobe necrosis.

There are various pathological causes which can give rise to a cerebral ischaemic lesion in a patient with temporal arteritis. The first is vasculitis of the cerebral vessels. The vertebral arteries are typically affected, as are the superficial temporal, the ophthalmic, and the posterior ciliary arteries. The internal carotid system (except for its ophthalmic branches), the vertebrobasilar system, and the circle of Willis can also be affected. ${ }^{78}$

Stroke symptomatology is found in $1-4.5 \%$ of patients with temporal arteritis. ${ }^{9}$ In the active phase of the disease the risk is high, up to $10-25 \% .^{10}$ In spite of this well documented investigations of the pathological effects and the extent of the arteritis are unusual. This investigation is carried out in less than $3 \%$ of patients. ${ }^{11}$ One consistent observation in published work is that strokes related to temporal arteritis are more often localised within the vertebrobasilar territory than within the carotid arterial system. ${ }^{7}{ }^{10}$ Basilar artery thrombosis has been given as a common cause of death. ${ }^{10}$

Emboli from a mural thrombus in myocardial infarction due to coronary arteritis can also give rise to a cerebral ischaemic lesion. Neuroophthalmologic events are seen during the first few days or weeks of the treatment with corticosteroids due to their thrombogenic properties. ${ }^{12-14}$ Some workers have recommended treatment with anticoagulant or antiplatelet drugs during the initial phase of steroid treatment for this reason. ${ }^{9}$

Atherosclerotic diseases of the cerebral arteries can also cause a cerebral ischaemic lesion. The age group at risk from temporal arteritis coincides with that at risk of cardiovascular disease due to atherosclerosis related to senility. The atherogenic effect of prolonged treatment with corticosteroids may also be a contributing factor.

In our patient we did not observe arteritic lesions in the basilar artery, only thrombosis. We could not rule out the possibility of arteritis in the extracranial vertebrobasilar area as we did not perform a histological study.

Stenosing coronary arteritis is well documented in giant cell arteritis but is unusual. ${ }^{15-17}$ Death due to acute myocardial infarction is still more unusual. ${ }^{16}$ In this patient the necropsy findings explained the aetiology of the chronic ischaemic heart disease which developed into congestive cardiac failure (fig 2).

Giant cell arteritis of the female reproductive tract is rare. In November 1989 a report of the fifteenth known case was published. ${ }^{18}$ The discovery was not related to any symptoms of the organ affected but was discovered by chance after surgical removal of the organ, as in previous reports. ${ }^{19}$ The patient did not have local symptoms at any time.

Pulmonary artery disease resulting in occlusion 


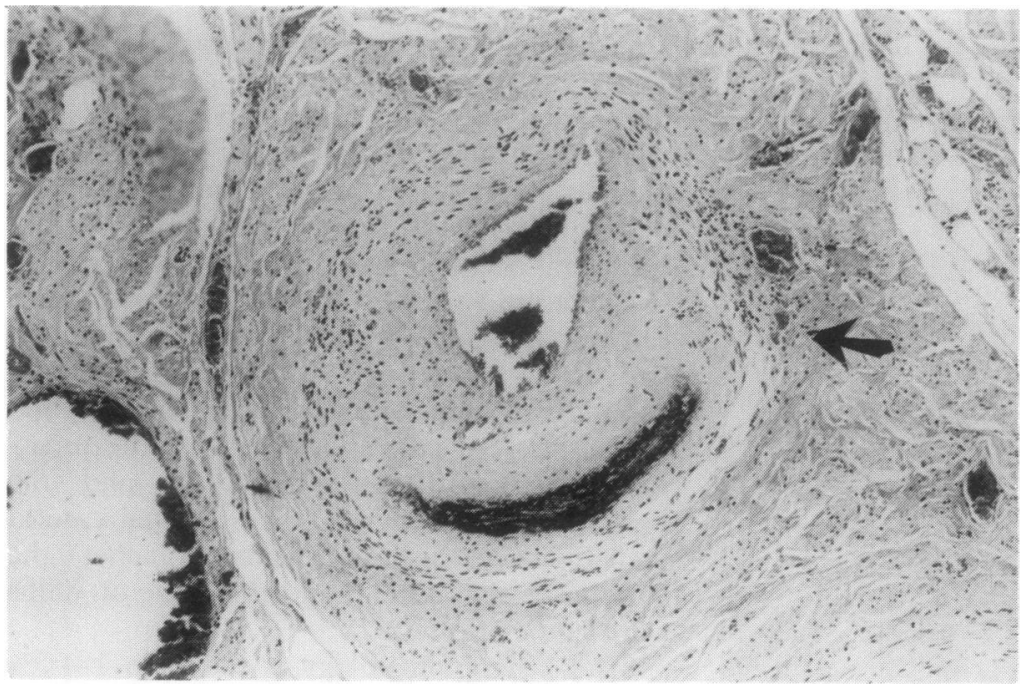

Figure 3 Female reproductive tract artery with calcification, chronic inflammatory infiltration, and presence of giant cells (arrow) (haematoxylin and eosin stain).

Figure 4 Peribronchial artery with occlusion of lumen and presence of granulomatous infiltration with giant cells of all coats (arrow) (haematoxylin and eosin stain).

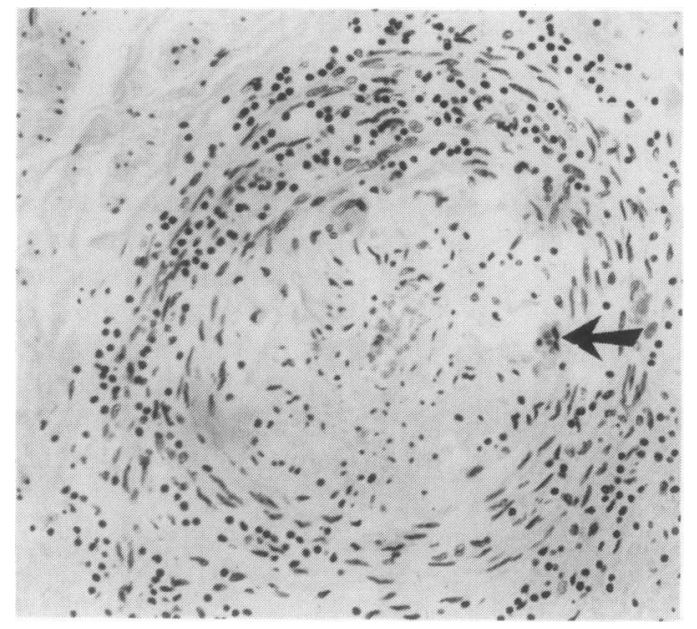

is found more often. ${ }^{20-22}$ Arteritic disease of the bronchial mucosa is less usual. This lesion may account for the respiratory symptomatology which is sometimes seen in the active course of the disease such as a dry cough or pharyngolaryngeal disorders. ${ }^{23}$ In our patient there was inflammatory disease of the peribronchial arteries without clinical manifestations (fig 4).

In addition to the systemic nature of giant cell arteritis this case illustrates the difficulty in deciding the appropriate dose and length of corticosteroid treatment. The recommended doses in the active phase are between 20 and $80 \mathrm{mg} /$ day. ${ }^{24} 25$

The duration of treatment with steroids is controversial due to the risk of side effects in longstanding treatment. ${ }^{26-29}$ Most workers favour treatment with corticosteroids for at least one to two years, but some patients need treatment for five to six years or even for life. We cannot forsee recurrences and it is difficult to know the treatment subgroup in which each patient will be.

In summary we have presented the case of a patient with a recurrence of giant cell arteritis. The necropsy showed an active multisystemic arteritis affecting the heart, lungs, and female reproductive tract. The triggering cause of death was an ischaemic necrosis of the encephalic trunk due to basilar artery thrombosis.

We thank Dr Gerald Salomon for his contribution to the translation of this paper. This work was supported in part by Caja Madrid, Madrid, Spain.

1 Cupps T R, Fauci A S. Las vasculitides. Buenos Aires: Intermédica, 1983.

2 Hunder G G. Giant cell arteritis and polymyalgia rheumatica. In: Kelley W N, Harris E D, Ruddy S, Sledge C B, eds. Textbook of rheumatology. Philadelphia: Saunders, 1989: $1200-8$.

3 Redondo C, Barbado F J, Peña J M, García-Delgado E, Gil A, Vázquez J J. Arteritis temporal: una vasculitis sistémica con diversas formas de presentación. Med Clin (Barc) 1982; 79: 411-4.

4 Fernandez-Herlihy L. Temporal arteritis: clinical aids to diagnosis. I Rheumatol 1988; 15: 1797-1801.

5 Hall S, Hunder G G. Is temporal biopsy prudent? Mayo Clin Proc 1984; 59: 793-6.

6 Chasnoff J, Voorzimer J J. Temporal arteritis: a local manifestation of a systemic disease. Ann Intern Med 1944; 20: 327-33.

7 Caselli R J, Hunder G G, Whisnant J P. Neurologic disease in biopsy-proven giant cell (temporal) arteritis. Neurology

8 Reich K A, Giansiracusa A F, Strongwater S L. Neurologic manifestations of giant cell arteritis. Am $\mathcal{F}$ Med 1990; 89: 67-72.

9 Ponge T, Barrier J, Mottier D, et al. Les accidents vasculaires cérébraux au cours de la maladie de Horton. A propos de huit observations. Semin Hop Paris 1984; 60: 2365-70.

10 Peña J M, Barbado F J, Domínguez A, Amer G, DíezTejedor E. Arteritis de células gigantes. In: Vasculitis $y$ sistema nervioso. Barcelona: Edit. MCR, 1987: 33-51.

11 Collado A, Santamaria J, Ribalta T, Cinta M, Cañete J D, Tolosa E. Giant-cell arteritis presenting with ipsilateral hemiplegia and lateral medullary syndrome. Eur Neurol 1989; 29: 266-8.

12 Gibb W, Urry P A, Lees A J. Giant cell arteritis with spinal cord infarction basilar artery thrombosis. $\mathcal{f}$ Neurol Neurosurg Psychiatry 1985; 48: 945-8.

13 Chadenas D, Picon L, Roux C, et al. Paraplégie flasque de survenue brutale. Accident du traitement corticoïde de la maladie de Horton? [letter] Presse Méd 1986; 15: 845.

14 Liozon F. Horton's disease. Ann Med Interne (Paris) 1989; 140: $122-41$.

15 Neri G, Zamprogno R, Borsato A, Arterite a cellule giganti come casa di infarto miocardico. G Ital Cardiol 1989; 19: 606-8.

16 Lie J T, Failoni D D, Davis D C. Temoporal arteritis with giant cell aortitis, coronary arteritis and myocardial infarction. Arch Pathol Lab Med 1986; 110: 857-60.

17 Villalta J, Valls V, Bernardo P, Cid M, Ingelmo M, Balcells A. Alteraciones electrocardiográficas en la arteritis de la temporal, antes y despues del tratamiento con corticoides. Med Clin (Barc) 1986; 87: 49-51.

$18 \mathrm{Kohn}$ N N. Giant cell arteritis of the female reproductive tract associated with temporal arteritis. $\mathcal{F}$ Rheumatol 1989; 16: 832-3.

19 Kyle V, Dutoit S H, Elias-Jones J, Hazleman B. Giant cell arteritis of myometrial and axillary arteries and polymyalgia rheumatica. Ann Rheum Dis 1987; 46: 256-8.

20 Landanyi M, Fraser R S. Pulmonary involvement in giant cell arteritis. Arch Pathol Lab Med 1987; 111: 1178-80.

21 Wagenaar S S, van den Bosch J M, Westermann C J. Pulmonary artery obstruction. Chest 1988; 93: 1314.

22 Glover M U, Muñiz J, Bessone L, Carta M, Casellas J, Maniscalco B S. Pulmonary artery obstruction due to giant
cell arteritis. Chest 1987; 91: 924-5.

23 Larson T S, Hall S, Hepper N G G, Hunder G G. Respiratory tract symptoms as a clue to giant cell arteritis. Ann Intern Med 1984; 101: 594-7.

24 Kyle V, Hazleman B L. Treatment of polymyalgia rheumatica and giant cell arteritis. I. Steroid regimens in the first two months. Ann Rheum Dis 1989; 48: 658-61.

25 Delecoeuillerie G, Joly P, Cohen de Lara A, Paolaggi J B. Polymyalgia rheumatica and temporal arteritis: retrospective analysis of prognostic features and different corticosteroid regimens (11 year survey of 210 patients). Ann Rheum Dis 1988; 47: 733-9.

26 Dutoit A, Dubus V, Croccel L, Routier G, Godeau P. Clinical and developmental aspects of Horton's disease. Retrospective study of 100 cases. Ann Cardiol Angeiol (Paris) 1988; 37: 199-204.

27 Andersson R, Malmvall B E, Bengtsson B A. Long-term corticosteroid treatment in giant cell arteritis. Acta Med Scand 1986; 220: 465-9.

28 Fernández-Herlihy $L$. Duration of corticosteroid therapy in giant cell arteritis. $\mathcal{F}$ Rheumatol 1980; 7: 361-4.

29 Graham E, Holland A, Avery A, Russel R W R. Prognosis in giant cell arteritis. $B M \mathcal{F}$ 1981; 282: 269-71. 